\title{
Erythropoietin protects against hemorrhagic blood-brain barrier disruption through the effects of aquaporin-4
}

\author{
Heling Chu ${ }^{1,2}$, Hongyan Ding ${ }^{1,2}$, Yuping Tang ${ }^{1}$ and Qiang Dong ${ }^{1}$
}

Erythropoietin (EPO) has protective effects against many neurological diseases, including intracerebral hemorrhage (ICH). Here, we aimed to test EPO's effects on blood-brain barrier (BBB) disruption morphologically and functionally following $\mathrm{ICH}$, which has not been well investigated. We also examined whether the effects were dependent on aquaporin-4 (AQP4). We detected the expression of perihematomal AQP4 and EPO receptor (EPOR) induced by EPO injection at 1, 3 and 7 days after $\mathrm{ICH}$. We also examined the effects of EPO on BBB disruption by $\mathrm{ICH}$ in wild-type mice, and tested whether such effects were AQP4 dependent by using AQP4 knock-out mice. Furthermore, we assessed the related signal transduction pathways via astrocyte cultures. We found that EPO highly increased perihematomal AQP4 and EPOR expression. Specifically, EPO led to BBB protection in both types of mice by functionally reducing brain edema and BBB permeability, as well as morphologically suppressing tight junction (TJ) opening and endothelial cell swelling, and increasing expression of the TJ proteins occludin and zonula occluden-1 (ZO-1). Statistical analysis indicated that AQP4 was required for these effects. In addition, EPO upregulated phosphorylation of C-Jun amino-terminal kinase (JNK) and p38-mitogenactivated protein kinase (MAPK) as well as EPOR and AQP4 proteins in cultured astrocytes. The latter was inhibited by JNK and p38-MAPK inhibitors. Our data suggest that EPO protects BBB from disruption after ICH and that the main targets are the TJ proteins occludin and ZO-1. The effects of EPO are associated with increased levels of AQP4, and may occur through activation of JNK and p38-MAPK pathways after binding to EPOR.

Laboratory Investigation (2014) 94, 1042-1053; doi:10.1038/labinvest.2014.84; published online 30 June 2014

Erythropoietin (EPO) was originally recognized as a humoral mediator involved in the maturation and proliferation of erythroid progenitor cells but is now appreciated for its neuroprotective effects in the central nervous system (CNS) as well. There has been a great deal of research confirming the protective effect of EPO in cerebral ischemic models, the mechanisms of which include apoptosis reduction, inflammation inhibition, angiogenesis enhancement and cerebral blood flow restoration. ${ }^{1,2}$ In recent years, studies have been conducted to determine EPO's effects on intracerebral hemorrhage (ICH), another type of stroke. ${ }^{3,4}$ However, the mechanisms involved need further investigation.

Disruption of the blood-brain barrier (BBB) is an important pathophysiological change after ICH and contributes to vasogenic brain edema formation, which is often serious and leads to poor prognosis. Previous research on EPO and BBB mainly focused on cerebral ischemic models, indicating that BBB disruption induced by middle cerebral artery occlusion can be attenuated by EPO. ${ }^{5,6}$ So far, there has only been one study describing how EPO acts on BBB disruption resulting from $\mathrm{ICH}$, and this study reveals that EPO decreased BBB permeability at 3 days after $\mathrm{ICH}^{7}{ }^{7}$ However, this effect was observed for only one isolated time point without dynamic observation and has not yet been supported by other research. In addition, the mechanisms involved remain unknown.

Aquaporin-4 (AQP4) is the most abundant water channel in the CNS and is predominantly expressed in the astrocyte foot processes surrounding capillaries, astrocyte processes comprising the glial limiting membrane and in ependymal cells. $^{8}$ As AQP4 is highly concentrated in the area of the BBB, it is believed to have important roles in maintaining BBB integrity throughout development and in mature individuals.., 10

\footnotetext{
${ }^{1}$ Department of Neurology, Huashan Hospital, State Key Laboratory of Medical Neurobiology, Fudan University, Shanghai, China

Correspondence: Dr Y Tang, MD or Dr Q Dong, MD, Department of Neurology, Huashan Hospital, State Key Laboratory of Medical Neurobiology, Fudan University, No. 12 Middle Wulumuqi Road, Shanghai 200040, China.

E-mail: tangyuping39@hotmail.com or qiang_dong163@163.com

${ }^{2}$ These authors contributed equally to this work.

Received 2 February 2014; revised 8 April 2014; accepted 10 April 2014
} 
Furthermore, our previous study shows that AQP4 deletion resulted in more serious disruption of BBB in morphology and function after $\mathrm{ICH}^{11}$

It has been reported that upregulation of AQP4 expression is observed in hypoxic-ischemic neonatal rats after receiving EPO. ${ }^{12}$ EPO significantly reduced upregulation of AQP4 induced by oxygen-glucose deprivation followed by reoxygenation. ${ }^{13}$ Based on the evidence that EPO levels are related to AOP4 expression, as well as that fact that both proteins are involved in BBB injury, we speculated that the effect of EPO on $\mathrm{BBB}$ disruption following $\mathrm{ICH}$ may result from regulation of AQP4 expression.

It has been shown that the biological effects of EPO and the EPO receptor (EPOR) mainly rely on activation of Janus kinase/signal transducer and activator of transcription (JAK/ STAT), phosphatidylinositol 3'-kinase (PI3K)/Akt and mitogen-activated protein kinase (MAPK) pathways, including extracellular signal-regulated kinase (ERK), C-Jun aminoterminal kinase (JNK) and p38-MAPK pathways. ${ }^{14,15}$ In addition, inhibitors of MAPKs suppressed AQP4 upregulation induced by manganese treatment or hyperosmotic solutions. ${ }^{16,17}$ Based on the above findings, we propose that EPO may regulate AQP4 expression by activating the pathways mentioned above.

To test these hypotheses, we injected EPO intraperitoneally after ICH and examined the changes of BBB and EPOR and $\mathrm{AQP} 4$ expression in wild-type $\left(\mathrm{AQP} 4^{+/+}\right)$mice. We also investigated whether EPO's effects on $\mathrm{BBB}$ are $\mathrm{AQP} 4$ dependent using AQP4 knock-out $\left(\mathrm{AQP}^{-1-}\right)$ mice. Furthermore, we studied the possible signal transduction pathways activated by EPO to regulate AQP4 expression through astrocyte cultures.

\section{MATERIALS AND METHODS}

\section{Animals and Experimental Groups}

Male AQP4 ${ }^{+1+}$ and AQP4 ${ }^{-1-}$ mice, 3- to 4-month-old, weighing $25-33 \mathrm{~g}$, were kindly provided by $\mathrm{Dr} \mathrm{Hu}$, Jiangsu Key Laboratory of Neurodegeneration, Department of Anatomy, Histology and Pharmacology of Nanjing Medical University in China. Mice were kept in the environment of a 12-h light/dark cycle with free access to food and water. Our animal studies and protocol was approved by the Institutional Animal Care and Use Committee of Fudan University.

$\mathrm{AQP} 4^{+1+}$ and $\mathrm{AQP} 4^{-1-}$ mice were randomly divided into five groups: group 1: control. Group 2: control plus EPO. Group 3: sham operation. Group 4: ICH. Group 5: ICH plus EPO. The parameters were detected 1, 3 and 7 days after drugs injection and each parameter of each group contained six mice.

\section{Mouse ICH Model and Drug Injection}

Mice were anesthetized with $10 \%$ chloralhydrate $(350 \mathrm{mg} / \mathrm{kg})$ and were placed in a stereotaxic frame (Alcott Biotech, Shanghai, China). Through a hole drilled in the skull, a
32 -gauge needle was implanted into the striatum, $2.0 \mathrm{~mm}$ lateral to the midline, $1.0 \mathrm{~mm}$ anterior to the coronal suture and at a depth of $4.0 \mathrm{~mm}$ from the surface of the brain. Each mouse was microinjected with $10 \mu \mathrm{l}$ of autologous whole blood taken from the tail vein over $10 \mathrm{~min}$ using a $10 \mu \mathrm{l}$ microinfusion pump (ALC-IP600, Alcott Biotech). Then the needle was pulled out without blood reflux after $5 \mathrm{~min}$ dwelling and the wound was sutured. Only the mouse with neurological deficit was regarded as a successful model. The mice in the sham operation group had the same operation but no blood was injected. According to previous studies ${ }^{3}$ and our preliminary experiment (four doses: 100, 500, 5000 and $15000 \mathrm{IU} / \mathrm{kg}$ ), recombinant human EPO (rhEPO, Sunshine Pharmaceuticals, Shenyang, China) was injected intraperitoneally with a dose of $5000 \mathrm{IU} / \mathrm{kg}$ at $2 \mathrm{~h}$ after ICH induction and daily afterward for 7 days (see Supplementary Information). The same dose of normal saline was injected intraperitoneally as control.

\section{Astrocyte Culture and Groups}

Astrocyte culture was prepared as previously reported. ${ }^{18}$ Cerebral cortices from neonatal Sprague-Dawley rat brains were removed and carefully dissected. The tissue was dissociated in DMEM containing $0.0025 \%$ trypsin/EDTA (Gibco) and passed through a $70 \mathrm{~mm}$ pore nylon mesh. After centrifugation, the cell pellet was resuspended in DMEM/F12 medium containing $10 \%$ fetal bovine serum, $50 \mathrm{U} / \mathrm{ml}$ penicillin and $50 \mathrm{mg} / \mathrm{ml}$ streptomycin (all from Gibco), and then plated onto $25 \mathrm{ml}$ tissue culture flasks. The medium was renewed every 2 to 3 days. After incubation for 5 to 7 days, the cells were trypsinized and subcultured in $60 \mathrm{~mm}$ diameter culture dishes. The cell population consisted of over 95\% astrocytes as determined by immunocytochemical staining with anti-glial fibrillary acidic protein antibody (Millipore, Billerica, USA).

The astrocytes were randomly divided into seven groups. Group 1: normal astrocytes. Group 2: EPO (10 IU/ml). Group 3: EPO plus SP600125 $(20 \mu \mathrm{mol} / \mathrm{l}$, Invivogen, San Diego, USA), a JNK inhibitor. Group 4: EPO plus SB239063 ( $10 \mu \mathrm{mol} / \mathrm{l}$, Enzo Life Sciences, NY, USA), a p38-MAPK inhibitor. Group 5: EPO plus U0126 (10 $\mu \mathrm{mol} / \mathrm{l}$, Invivogen), an ERK inhibitor. Group 6: EPO plus AG490 (0.1 $\mu \mathrm{mol} / \mathrm{l}$, Invivogen), a JAK2 inhibitor. Group 7: EPO plus Ly294002 (30 $\mu \mathrm{mol} / \mathrm{l}$, Invivogen), a PI3K inhibitor. The doses of drugs were according to our preliminary experiment (four doses of rhEPO: $0.4,2,10$, and $50 \mathrm{IU} / \mathrm{ml}$ ) and previous reports (see Supplementary Information). ${ }^{19-22}$

\section{Determination of BBB Permeability with the use of Evans Blue}

Evans blue (EB, Sigma-Aldrich, St Louis, USA) in normal saline $(2 \%, 4 \mathrm{ml} / \mathrm{kg})$ was injected intravenously at 1,3 and 7 days after operation. The mice were anesthetized $1 \mathrm{~h}$ later and perfused with $200 \mathrm{ml}$ of normal saline solution through the left cardiac ventricle. They were decapitated and 
ipsilateral (hemorrhagic) hemispheres were homogenized in methylformamide ( $1 \mathrm{ml} / 100 \mathrm{mg}$ brain tissue), incubated for $24 \mathrm{~h}$ at $60^{\circ} \mathrm{C}$ and centrifuged for $5 \mathrm{~min}$ at $1000 \mathrm{~g}$. The absorbance $(A)$ of supernatants was analyzed at $632 \mathrm{~nm}$ by spectrophotometry. The amount of EB $(\mu \mathrm{g} / \mathrm{g})$ was calculated through standard curve established by known concentrations of $\mathrm{EB}$.

\section{Brain Water Content}

Brain was rapidly removed from the skull at 1, 3 and 7 days after operation and the olfactory bulbs and brain stem with the cerebellum were eliminated before water contents were measured, which were performed $>2$ min after the decapitation. After the wet weight of ipsilateral (hemorrhagic) hemisphere was measured, the tissue was then dried at $100{ }^{\circ} \mathrm{C}$
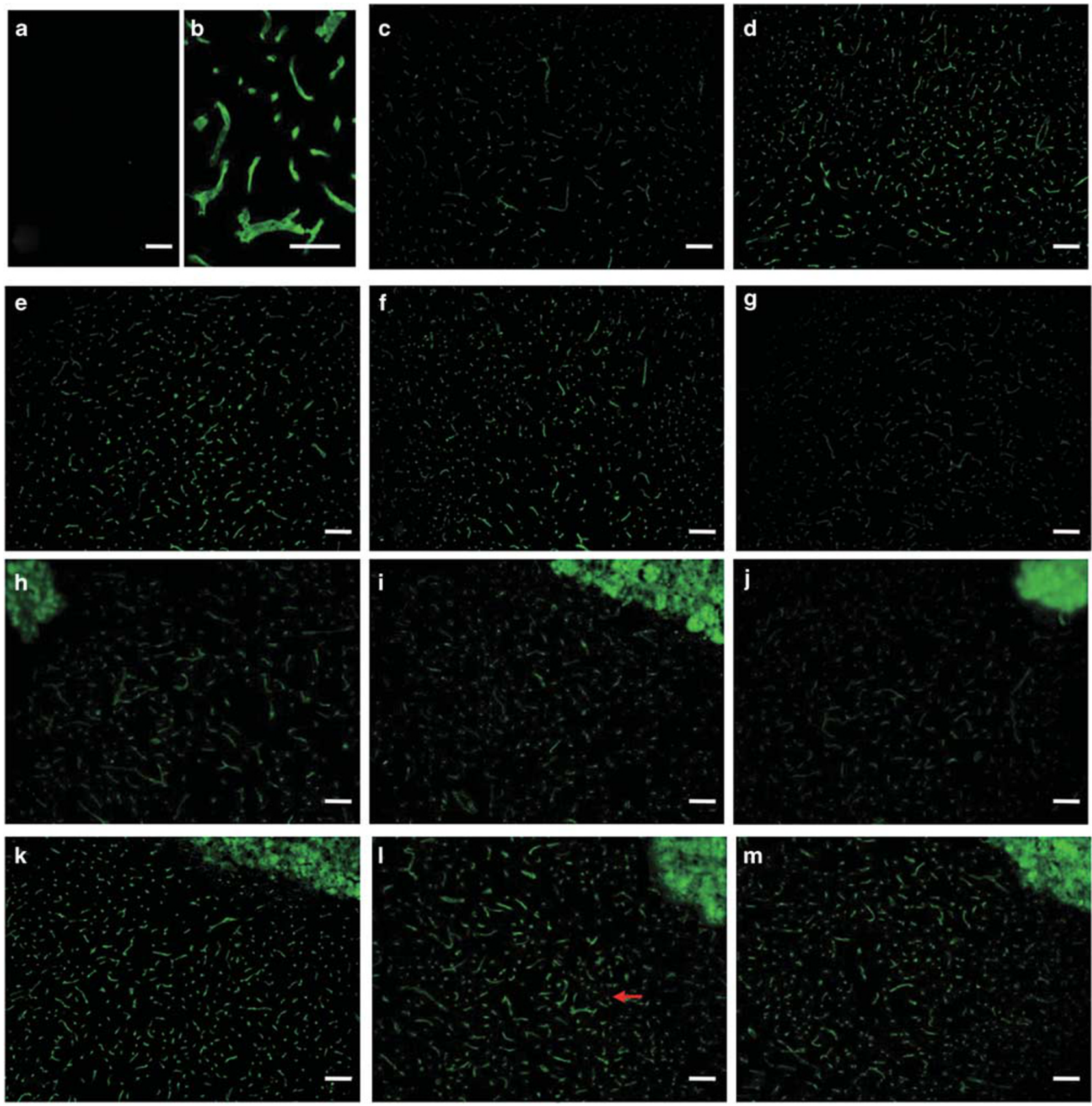

Figure 1 Immunofluorescence of AQP4 protein expression in each AQP4 ${ }^{+/+}$group. (a) Negative control without primary antibody showed no detectable AQP4 labeling. (b) High magnification for ICH + EPO group 3 days after operation (red arrow, L) shows that AQP4 labeling was concentrated in glial end-feet surrounding intracerebral capillaries. (c-f) Control, control plus EPO 1, 3 and 7 days after first injection. (g-j) Sham operation, ICH 1, 3, and 7 days. (k-m) ICH plus EPO 1, 3 and 7 days after ICH. The AQP4 staining was vascular (green fluorescence) and abundantly expressed after ICH and rhEPO injection at normal striatum as well as surrounding the hematoma at any chosen time point. Scale bar: (b) $50 \mu \mathrm{m},(\mathbf{a}, \mathbf{c}-\mathbf{m}) 100 \mu \mathrm{m}$. 
for $24 \mathrm{~h}$, and its dry weight was measured. Brain water content (as a percentage $)=($ wet weight - dry weight $) /$ wet weight $\times 100 \%$.

\section{Electron Microscopy}

The mice were perfused through the heart with $2 \%$ paraformaldehyde $/ 2 \%$ glutaraldehyde buffered with $0.1 \mathrm{~mol} / \mathrm{l}$ phosphate buffer, pH 7.2 at 1, 3 and 7 days after operation. After perfusion, the brain was removed and further immersed in the same fixative at $4{ }^{\circ} \mathrm{C}$ over night. After being washed thoroughly with the same buffer, containing $7.5 \%$ sucrose, samples were post-fixed with $1 \% \mathrm{OsO}_{4}$ in the same buffer, containing $7.5 \%$ sucrose, at $4{ }^{\circ} \mathrm{C}$ for $2 \mathrm{~h}$; the brain was block stained with $2 \%$ aqueous solution of uranyl acetate for $1 \mathrm{~h}$. a
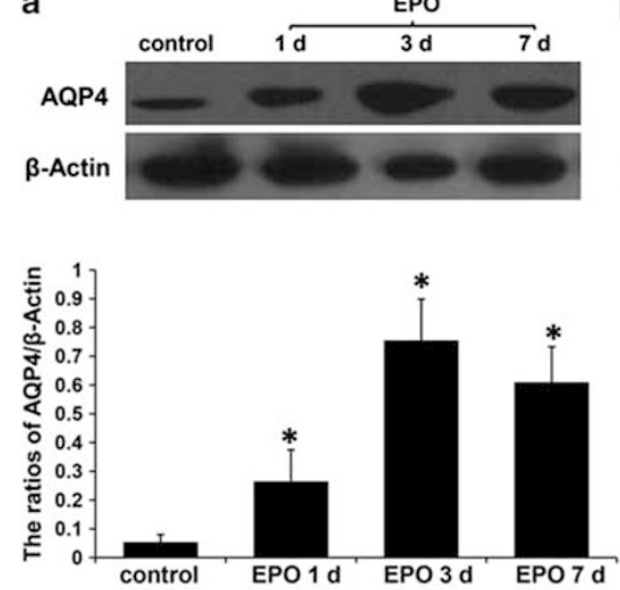

b

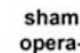

sham

ICH

AQP4

$\beta$-Actin
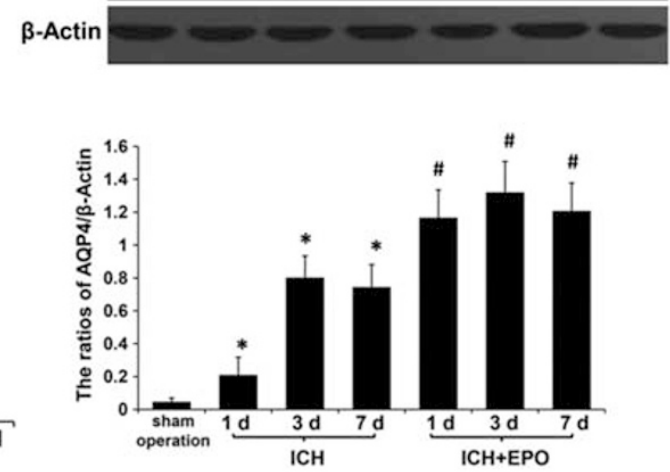

c

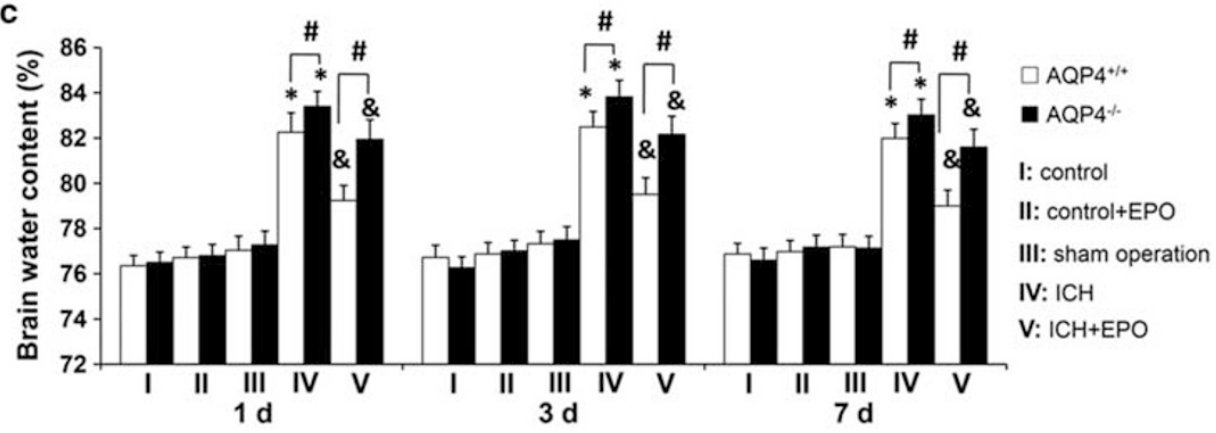

d

Time after operation

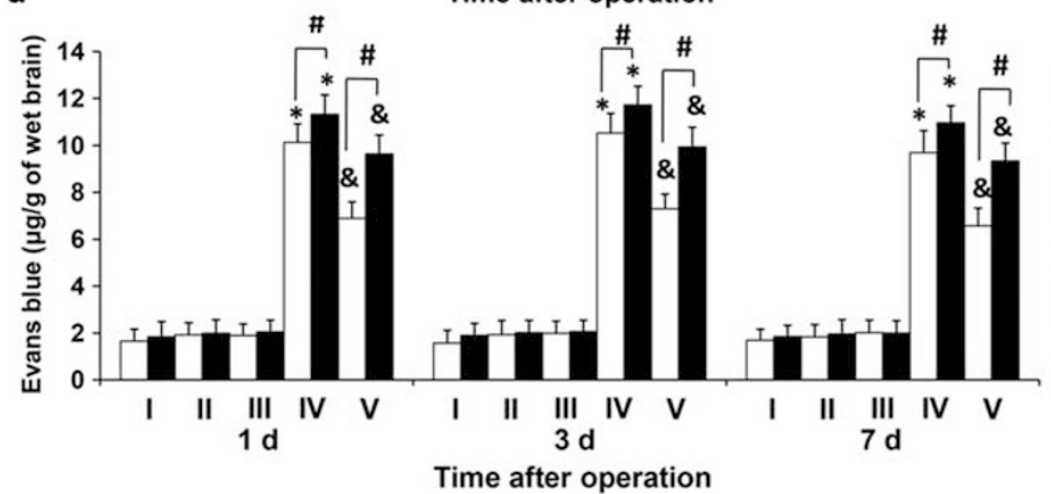

$\square \mathrm{AQP4}^{+/ *}$

- $\mathrm{AQP} 4$

I: control

II: control+EPO

III: sham operation

IV: ICH

V: $\mathrm{ICH}+\mathrm{EPO}$

Figure 2 Effects of EPO on AQP4 expression, brain water content and EB extravasation. (a, b) Western blot analysis shows that rhEPO upregulated AQP4 protein expression in the normal striatum $\left(n=6,{ }^{*} P<0.05\right.$ vs control) and in the area surrounding the hematoma in AQP4 ${ }^{+}+$mice at 1,3 and 7 days after the first injection ( $n=6,{ }^{*} P<0.05$ vs sham operation, $\# P<0.05$ vs $\mathrm{ICH}$ ). (c, d) RhEPO injected intraperitoneally significantly reduced brain water content (c) and EB extravasation (d) at 1, 3 and 7 days after ICH in both types of mice $\left(n=6,{ }^{*} P<0.05\right.$ vs sham operation, \& $P<0.05$ vs ICH). All of the injuries mentioned above were more severe in AQP4 ${ }^{-/-}$mice compared with $\mathrm{AQP} 4^{+/+}$mice, whether they were in the ICH group or the ICH plus EPO group ( $\left.n=6,{ }^{\#} P<0.05\right)$. Two-way ANOVA with replication yields $F(P)$ values of $5.90(0.025), 5.17(0.034), 7.199(0.014)(\mathbf{c})$ and $5.87(0.025), 5.02$ (0.037), $5.28(0.033)(\mathbf{d})$, suggesting a relationship between EPO administration and the presence of AQP4. 
Then, the brain was de-hydrated with a graded series of ethanol and embedded in Epon 812. Serial ultrathin sections were cut with the ultramicrotome, stained with lead citrate and uranyl acetate and observed with a Hitachi H-7100 electron microscope.

\section{Western Blotting}

Protein extraction: (1) in vivo experiment: brain hemispheres (hemorrhage) were homogenized in RIPA lysis buffer (Beyotime, Suzhou, China) and $1 \mathrm{mmol} / \mathrm{l}$ phenylmethanesulfonyl fluoride (PMSF). (2) In vitro experiment: the culture fluid of each group of astrocytes was discarded $48 \mathrm{~h}$ after drugs administration and the cells were treated with RIPA lysis buffer and PMSF. In addition, astrocytes of group 2 were treated in the same way at $0,12,24,48$ and $72 \mathrm{~h}$ after drugs administration. After centrifugation, the supernatant was used for analysis. Proteins $(50 \mu \mathrm{g})$ were loaded onto $4 \%$ stacking/12\% separating SDS-polyacrylamide gels for electrophoresis, and then transferred onto nitrocellulose transfer membranes. After being blocked, membranes were incubated overnight at $4{ }^{\circ} \mathrm{C}$ with anti-AQP4 (1:1000, Sigma-Aldrich), anti-EPOR (1:1000, Millipore), anti-occludin (1:1000,
Millipore), anti-zonula occluden-1 (ZO-1; 1:1000, Millipore), anti-claudin-5 (1:1000, Millipore), anti-p-JNK (1:1000, CST, Boston, USA), anti-p-p38 (1:1000, CST), anti-p-ERK (1:1000, CST), anti-p-STAT5 (1:1000, CST) and anti-p-Akt (1:1000, CST) rabbit polyclonal antibodies. Membranes were then incubated for $1 \mathrm{~h}$ at room temperature with horseradish peroxidase (HRP) labeled goat anti-rabbit secondary antibody (1:4000, Vector, Burlingame, USA). The membranes were placed into ECL solution for $5 \mathrm{~min}$, and then exposed. The intensity of blots was quantified using the Leica Image Processing and Analysis System. $\beta$-Actin was used as an internal control.

\section{Immunofluorescence}

Specimen preparation: (1) in vivo experiment: $\mathrm{AQP} 4^{+1+}$ mice were anesthetized at 1, 3 and 7 days after operation and perfused with normal saline solution and $4 \%$ ice-cold paraformaldehyde through the left cardiac ventricle. Brain tissues were removed and gradient dehydrated. Serial coronal sections $(10 \mu \mathrm{m})$ were then cut on a freezing microtome (CM 1900, Leica, Wetzlar, Germany). (2) In vitro experiment: the coverslips full of astrocytes were taken out at $48 \mathrm{~h}$ after drugs
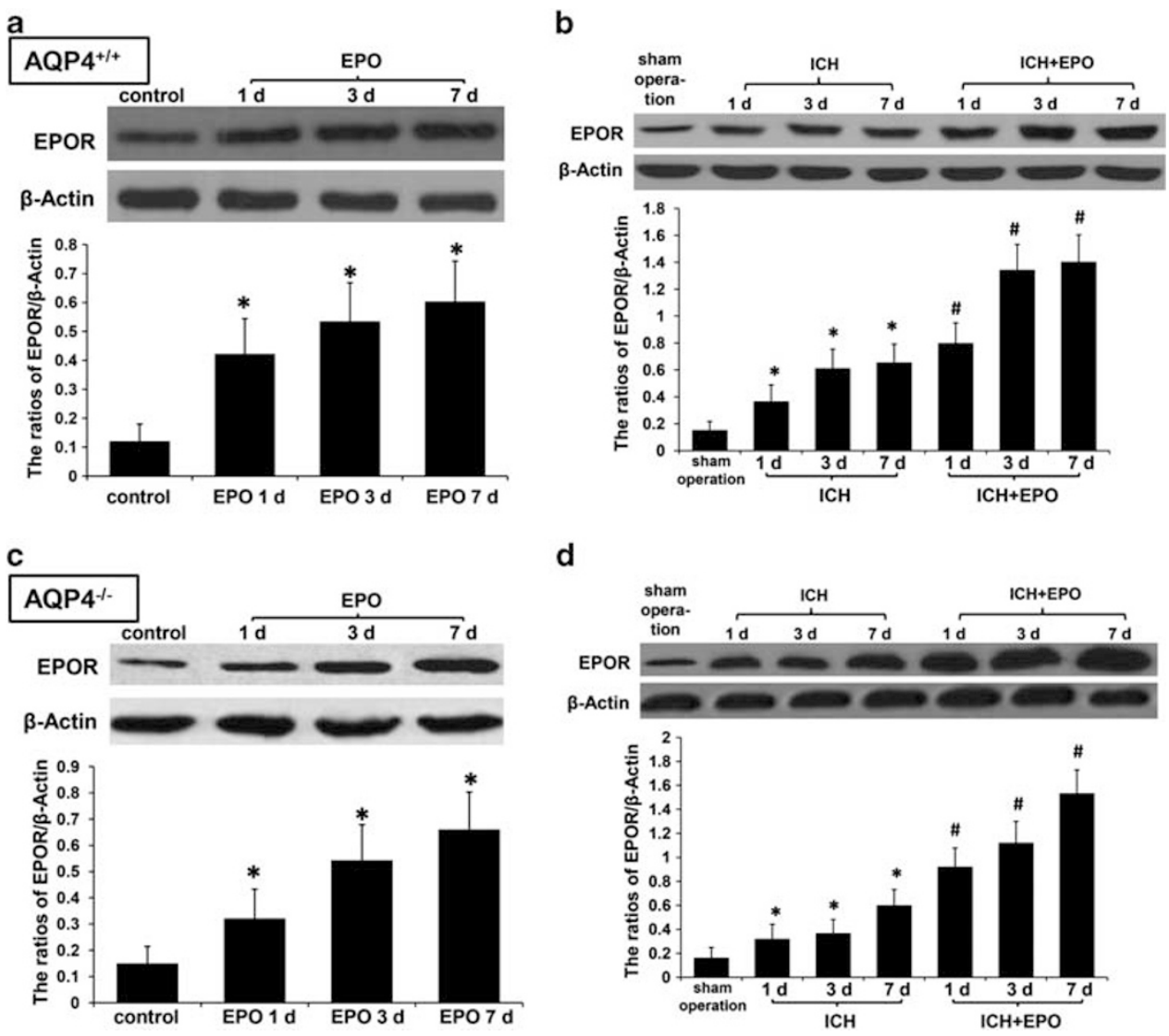

Figure 3 Effects of EPO on EPOR expression. Western blot analysis shows that EPO upregulated its receptor in normal striatum at 1, 3 and 7 days after injection in both AQP4 ${ }^{+/+}$(a) and AQP4 ${ }^{-/-}$mice (c) $\left(n=6,{ }^{*} P<0.05\right.$ vs control). In addition, ICH induced EPOR upregulation, and higher level of EPOR was found surrounding the hematoma at any time point after intraperitoneal rhEPO injection in both AQP4 ${ }^{+1+}$ (b) and AQP4 ${ }^{-1-}$ mice (d) ( $n=6,{ }^{*} P<0.05$ vs sham operation, ${ }^{\#} P<0.05$ vs ICH). 
administration. Each group of astrocytes was fixed by $4 \%$ paraformaldehyde for $30 \mathrm{~min}$. After washing, the sections were blocked by $10 \%$ goat serum. Sections were incubated overnight at $4{ }^{\circ} \mathrm{C}$ with anti-AQP4 rabbit polyclonal antibody (1:500, Sigma-Aldrich), and then incubated $1 \mathrm{~h}$ at $37^{\circ} \mathrm{C}$ with fluorescein isothiocyanate (FITC) coupled secondary goat anti-rabbit IgG (1:500, Invitrogen). The astrocytes were also stained with 4',6-diamidino-2-phenylindole (DAPI) for highlighting the nuclei.

\section{Statistical Analysis}

All data were presented as mean \pm s.e.m. and analyzed with SPSS12.0. Differences between groups were compared by using one-way ANOVA. When the ANOVA identified a
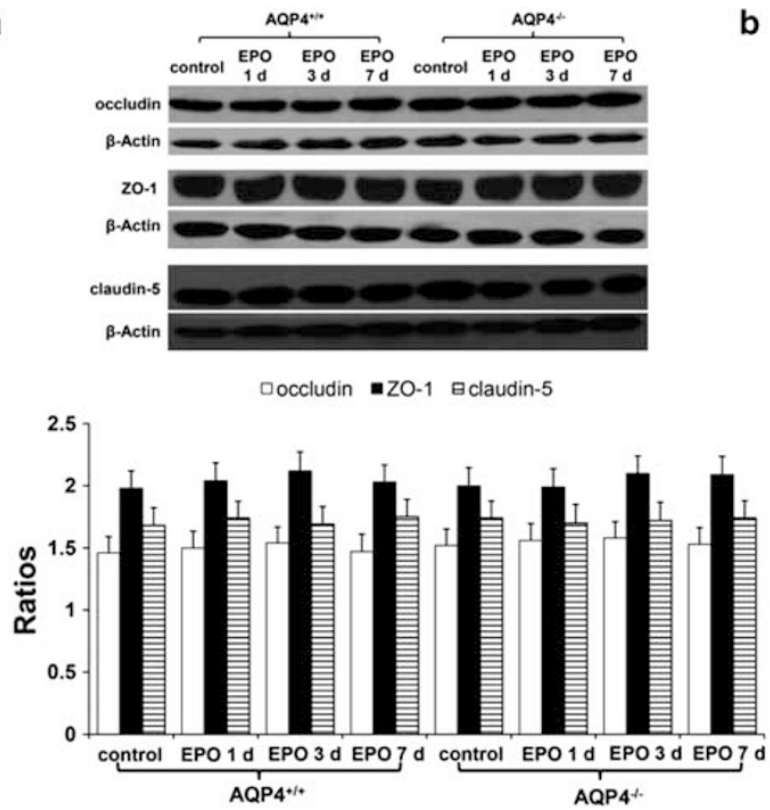

C

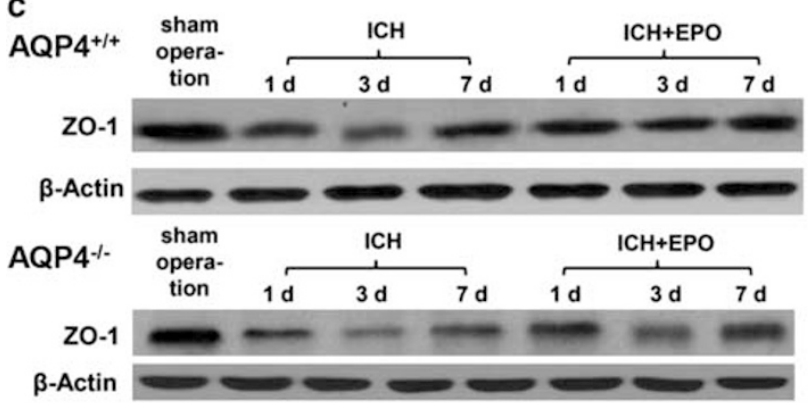

b
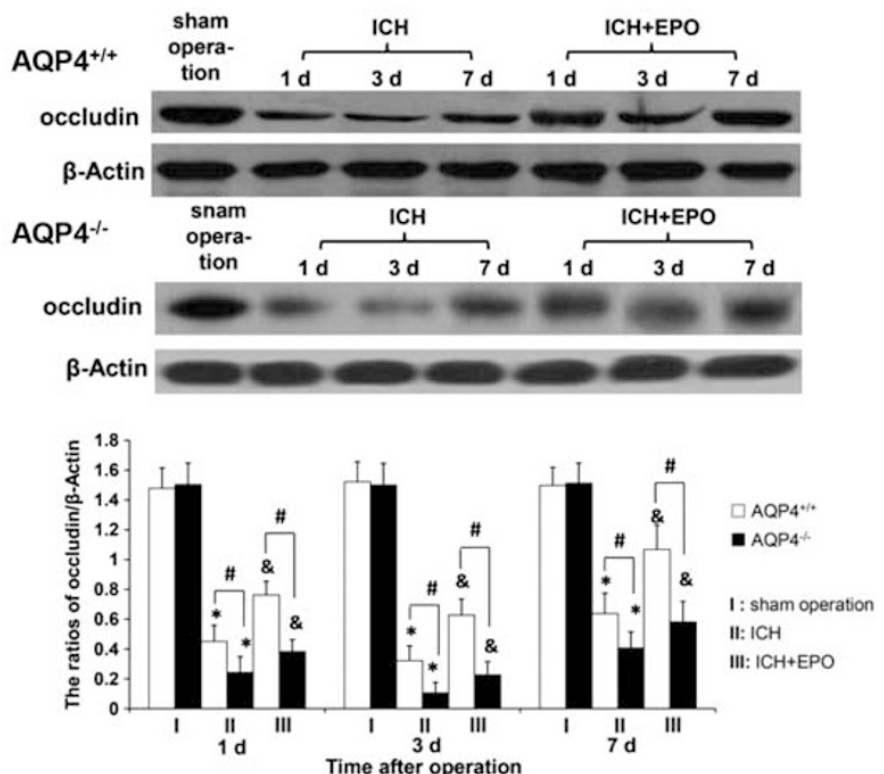
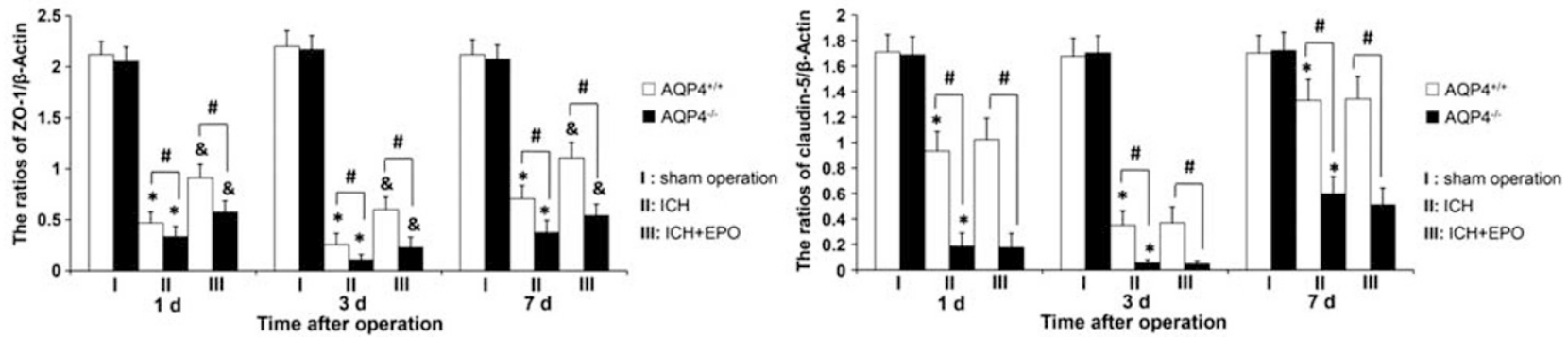

Figure 4 Expression of TJ proteins in AQP4 ${ }^{+/+}$and $\mathrm{AQP4} 4^{-/-}$mice. (a) RhEPO had no influence on expression of occludin, ZO- 1 and claudin-5 in two types of normal mice. (b-d) Downregulation of the three TJ proteins was induced by ICH $\left(n=6,{ }^{*} P<0.05\right.$ vs sham operation) and higher levels of these proteins were detected in AQP4 ${ }^{+/+}$mice than AQP4 ${ }^{-1-}$ mice after $\mathrm{ICH}\left(n=6,{ }^{\#} P<0.05\right)$. Intraperitoneal rhEPO injection upregulated expression of occludin and ZO-1, but not claudin-5 in AQP4 ${ }^{+1+}$ mice than AQP4 ${ }^{-1-}$ at 1,3 and 7 days after ICH $\left(n=6,{ }^{\&} P<0.05\right.$ vs ICH), while the levels were still higher in AQP4 ${ }^{+1+}$ mice $\left(n=6,{ }^{\#} P<0.05\right)$. Two-way ANOVA with replication revealed that the $F$-values were $4.59,5.93,5.19$ and $4.80,7.44,4.87$ with the corresponding $P$-values of $0.045,0.024,0.034$ and $0.041,0.013,0.039$, indicating a relationship between EPO administration and expression of the AQP4 gene. (b) Western blot analysis for occludin. (c) Western blot analysis for ZO-1. (d) Western blot analysis for claudin-5. 
a

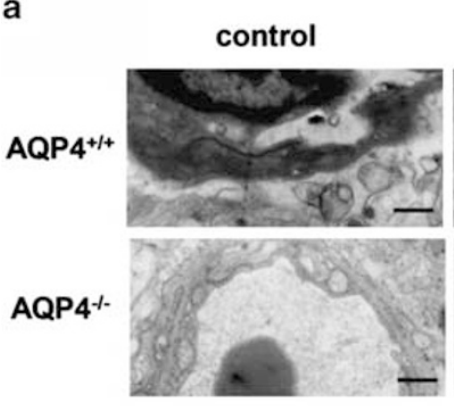

b

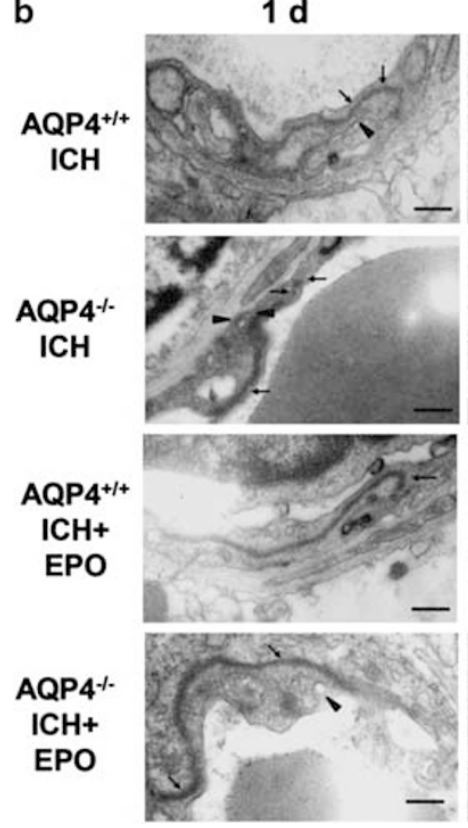

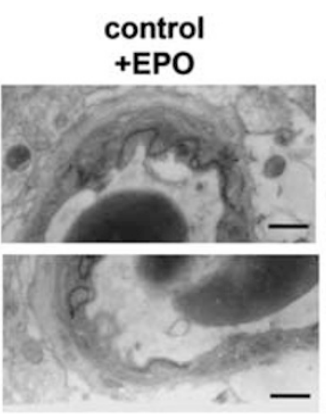

$3 \mathrm{~d}$

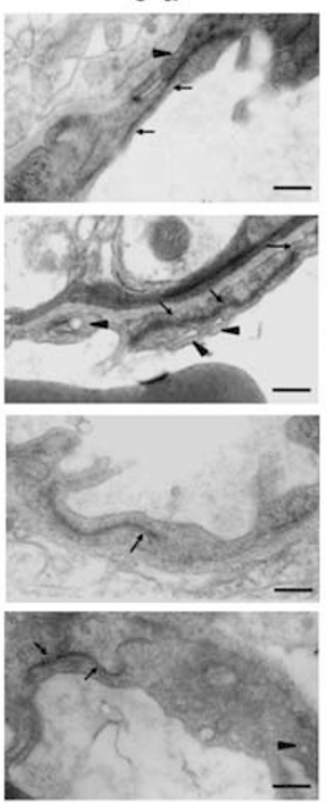

sham operation

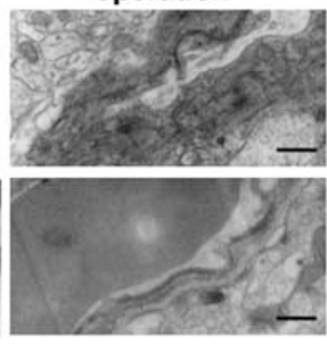

$7 \mathrm{~d}$

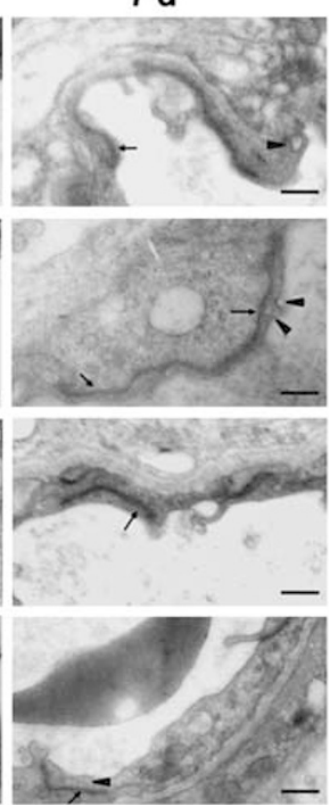

Figure 5 Ultrastructural changes of $\mathrm{BBB}$ in $\mathrm{AQP} 4^{+/+}$and $\mathrm{AQP} 4^{-1-}$ mice. (a) In normal BBB, capillary endothelial cell was normal and showed no swelling. TJ appeared as a series of electron-dense zones in the plasma membrane of adjacent endothelial cells. RhEPO had no effect on normal BBB. Scale bar: $1 \mu \mathrm{m}$. (b) After ICH, electron micrographs show capillary endothelial cell swelling and the majority of the vessels were lined by irregular endothelium in both thin and thick cytoplasmic regions with numerous vesicles and vacuoles (arrowheads). TJ appeared modified owing to the presence of detachments of the external plasma membranes leaflets (arrows). After intraperitoneal rhEPO injection, endothelial cell morphology changed; the cells were flattened with fewer vesicles and vacuoles and attenuation of swelling. Extensive TJ was developed with points and lines of fusion between the plasma membrane external leaflets. AQP4 ${ }^{-/-}$mice revealed more serious BBB disruption than AQP4 ${ }^{+/+}$mice in either the ICH or ICH plus EPO group. Scale bar: $0.5 \mu \mathrm{m}$.

significant between-group differences, Tukey's honestly significant difference tests were used for intergroup comparisons. Two-tailed Student's $t$-tests were for comparisons between $\mathrm{AQP} 4^{+/+}$and $\mathrm{AQP} 4^{-1-}$ mice in each group. In addition, we added two-way ANOVA with replication in sections containing $\mathrm{AQP} 4^{+/+}$and $\mathrm{AQP} 4^{-/-}$mice to examine whether interactions existed between EPO injection and presence of $\mathrm{AQP} 4$ gene.

\section{RESULTS}

\section{Expression of AQP4 Protein in Each Group of AQP4 ${ }^{+/+}$ Mice}

Immunofluorescence shows that AQP4 staining was vascular, based on green fluorescence abundantly expressed in groups of control plus EPO, ICH and ICH plus EPO at each time point after operation. Both western blotting and immunofluorescence revealed an increase of AQP4 protein at the striatum after 1,3 and 7 days by intraperitoneal rhEPO injection in normal mice $(P<0.05)$. Furthermore, perihematomal AQP4 protein expression was upregulated by rhEPO at the three time points after ICH $(P<0.05)$. Statistical differences were found upon semiquantitive analysis of western blot (Figures 1 and $2 \mathrm{a}$ and $\mathrm{b}$ ).

\section{Expression of EPOR Protein in Each Group of AQP4 ${ }^{+1+}$ Mice and AQP4 ${ }^{-1-}$ Mice}

RhEPO significantly upregulated EPOR at the striatum 1, 3 and 7 days after intraperitoneal injections in normal mice 

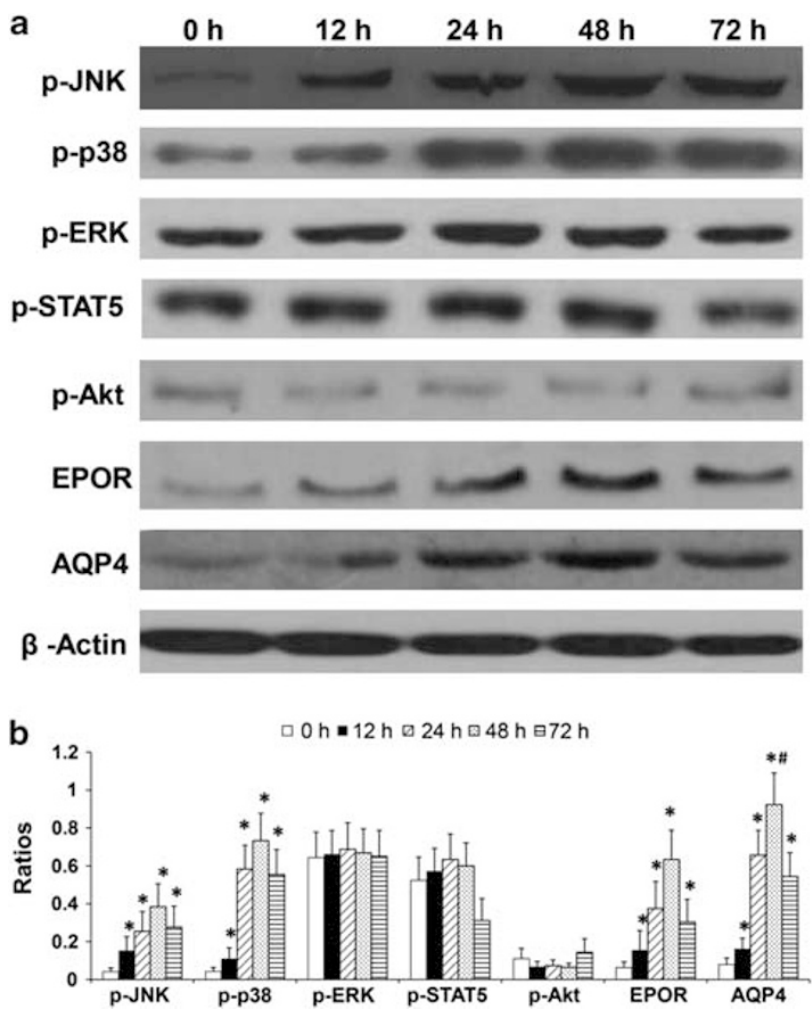

Figure 6 Western blot of phosphorylation of MAPKs, STAT5, Akt, EPOR and AQP4 influenced by rhEPO. RhEPO upregulated p-JNK, p-p38 and EPOR at $12 \mathrm{~h}$ after administration ( $n=6,{ }^{*} P<0.05$ vs $0 \mathrm{~h}$ ), while no upregulation of $p$-ERK, p-STAT5 or p-Akt was observed within $72 \mathrm{~h}$ after rhEPO administration. In addition, expression of AQP4 protein was increased by rhEPO after $12 \mathrm{~h}$ and peaked at $48 \mathrm{~h}\left(n=6,{ }^{*} P<0.05\right.$ vs $0 \mathrm{~h}$; ${ }^{\#} P<0.05$ vs $0,12,24$ and 72 h). (a) Western blot image. (b) Semiquantification analysis.

$(P<0.05)$. ICH induced a higher level of EPOR expression surrounding the hematoma and a further increase of EPOR was detected because of rhEPO injection at each time point $(P<0.05)$. In addition, the effect of rhEPO on EPOR expression in $\mathrm{AQP} 4^{-1-}$ mice was very similar to $\mathrm{AQP} 4^{+/+}$ mice, suggesting AQP4 deletion did not influence this effect (Figure 3).

\section{Brain Water Content and EB Extravasation Amount in $\mathrm{AQP4}^{+/+}$and AQP4 ${ }^{-1-}$ Mice}

RhEPO had no effect on normal mice. AQP4 ${ }^{-1-}$ mice had more brain water content and EB extravasation amount after ICH comparing with $\mathrm{AQP} 4^{+/+}$groups $(P<0.05)$. Injection of rhEPO intraperitoneally reduced brain water content and EB extravasation amount in both types of mice at 1,3 and 7 days after ICH $(P<0.05)$, but the above differences still existed $(P<0.05)$. To investigate whether these effects of EPO involved AQP4, we studied the interactions between EPO injection and determined the presence of AQP4 gene by two-way ANOVA with replication. The $F(P)$ values were 5.90 (0.025), 5.17 (0.034), 7.199 (0.014) (brain water content) and $5.87(0.025), 5.02(0.037), 5.28(0.033)$ (EB extravasa- tion amount), suggesting presence of interactions (Figures $2 \mathrm{c}$ and d).

\section{Expression of Occludin, ZO-1 and Claudin-5 in AQP4 ${ }^{+1+}$ and AQP4 ${ }^{-I-}$ Mice}

EPO had no effect in both types of normal mice in these experiments. All of the three tight junction (TJ) proteins were downregulated after ICH and their levels were higher in $\mathrm{AQP} 4^{+1+}$ mice than $\mathrm{AQP} 4^{-1-}$ mice $(P<0.05)$. Injection of rhEPO intraperitoneally increased expression of occludin and ZO-1 rather than claudin- 5 in both types of mice at 1,3 and 7 days after $\mathrm{ICH}$, while the levels were still higher in AQP4 ${ }^{+1+}$ mice $(P<0.05)$. Similarly, two-way ANOVA with replication revealed $F$-values were 4.59, 5.93, 5.19 and 4.80, 7.44, 4.87 with the corresponding $P$-values of $0.045,0.024$, 0.034 and $0.041,0.013,0.039$, suggesting interactions between EPO administration and presence of AQP4 gene existed (Figure 4).

\section{Ultrastructural Changes of BBB of AQP4 ${ }^{+/+}$and AQP4 ${ }^{-1-}$ Mice}

For normal $\mathrm{BBB}$ in $\mathrm{AQP} 4^{+/+}$and $\mathrm{AQP} 4^{- \text {an }}$ mice, capillary endothelial cells were normal, no swelling was observed. TJ appeared as a series of electron-dense zones, which lay in the plasma membrane of adjacent endothelial cells and sealed the intercellular cleft. RhEPO had no effect on normal BBB (Figure 5a). After ICH, electron micrographs show capillary endothelial cell swelling, irregular thickening of capillary and perivascular space widening in the BBB. The majority of the vessels were lined by irregular endothelium in both thin and thick cytoplasmic regions with numerous vesicles and vacuoles (arrowheads). TJ appeared modified owing to the presence of detachments of the external plasma membranes leaflets (arrows). After rhEPO was injected intraperitoneally, endothelial cells turned to be flattened with fewer vesicles and vacuoles and attenuation of swelling; also, an extensive TJ with points and lines of fusion between the plasma membrane external leaflets was seen, suggesting rhEPO suppresses the perivascular space widening, TJ opening and endothelial cell swelling. In addition, $\mathrm{AQP} 4^{-1-}$ mice revealed more serious BBB disruption than $\mathrm{AQP} 4^{+1+}$ mice in either ICH or ICH plus EPO group (Figure $5 b$ ).

\section{Expression of Phosphorylation of MAPKs, STAT5, Akt, EPOR and AQP4 by EPO Over Time}

Western blotting including semiquantitive analysis shows that in cultured astrocytes, p-JNK, p-p38 and EPOR were upregulated at $12 \mathrm{~h}$ after rhEPO administration $(P<0.05)$. Although no upregulation of p-ERK, p-STAT5 or p-Akt was observed within $72 \mathrm{~h}$ after rhEPO administration. Expression AQP4 protein was increased by rhEPO after $12 \mathrm{~h}$ and peaked at $48 \mathrm{~h}(P<0.05)$, in accord with the changing trend of p-JNK and p-p38 (Figure 6). 
a
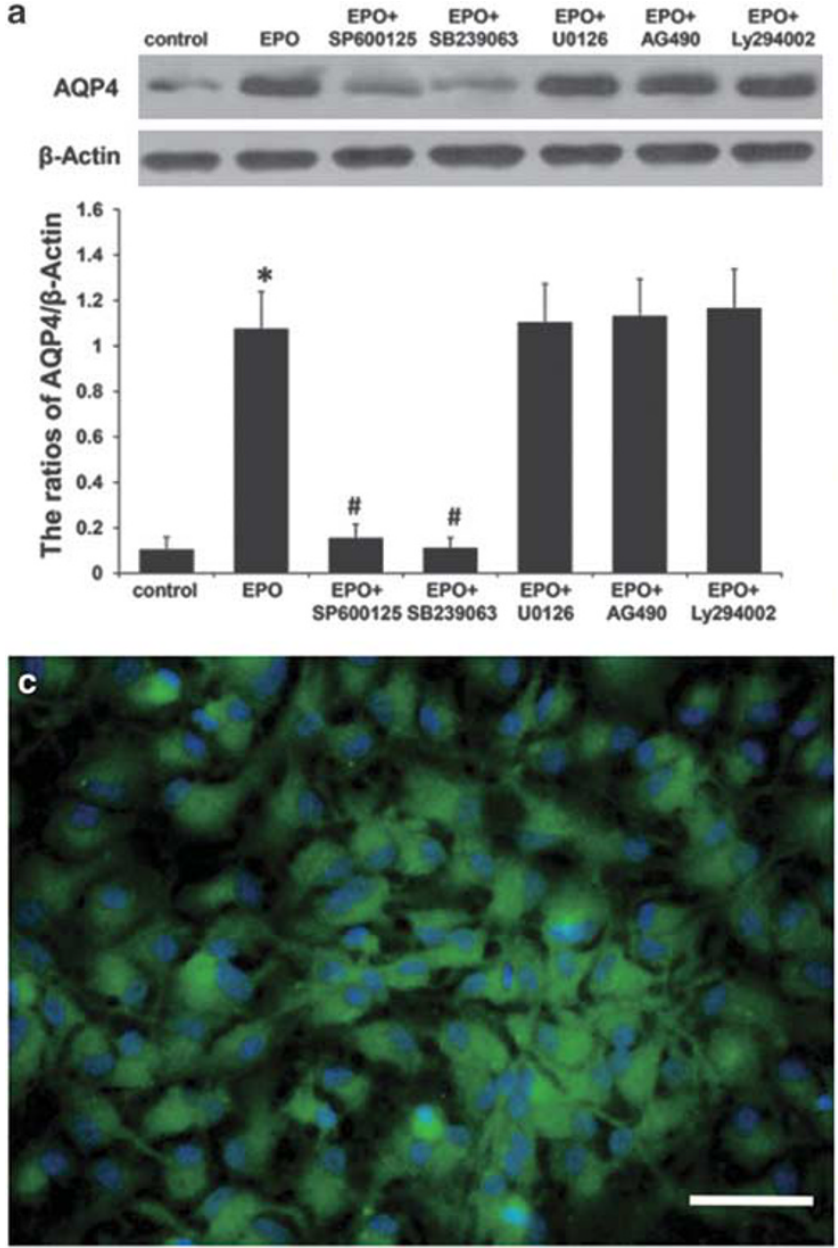
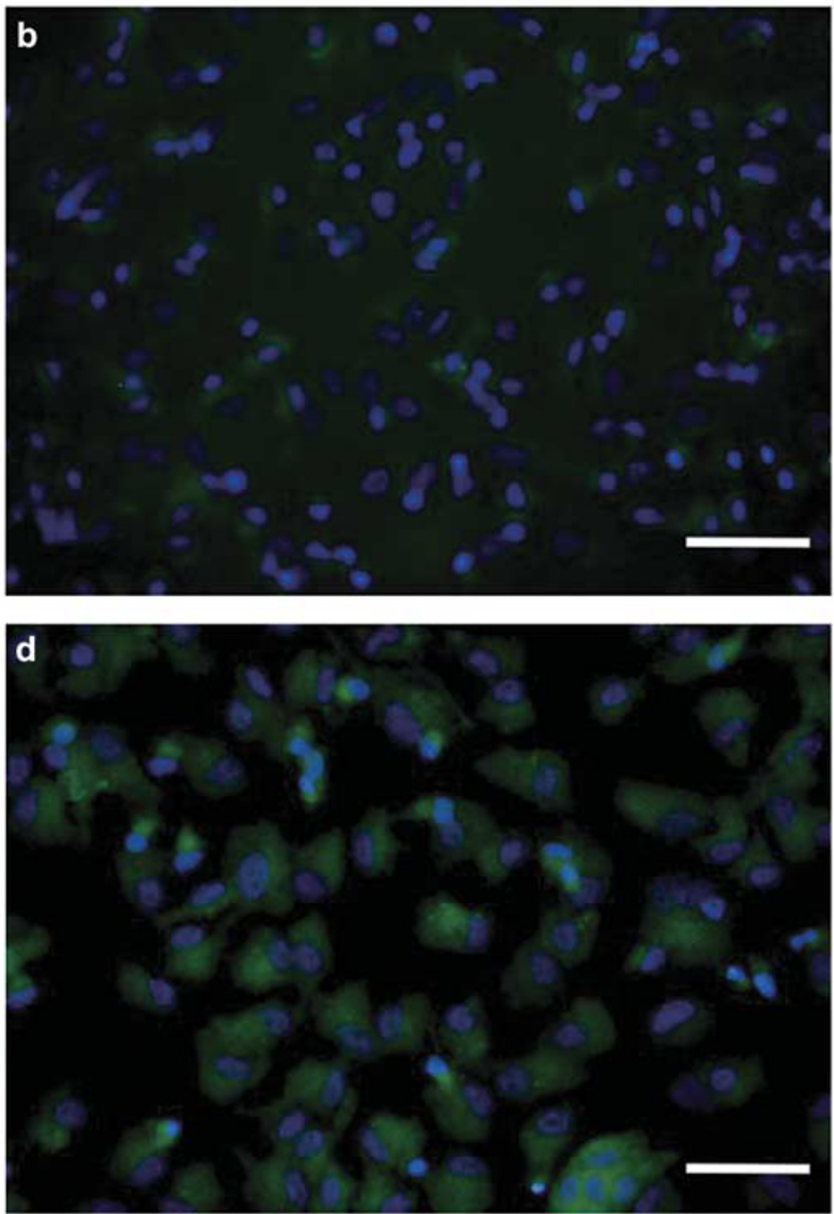

Figure 7 Effects of signal pathway inhibitors on AQP4 expression. Both western blot and immunofluorescence revealed that rhEPO increased AQP4 protein expression in astrocytes, which was inhibited by SP600125, a JNK inhibitor and SB239063, a p38-MAPK inhibitor ( $n=6$, ${ }^{*} P<0.05$ vs control, ${ }^{\#} P<0.05$ vs EPO). (a) Western blot analysis. (b) Control group. (c) EPO group. (d) EPO plus SP600125 (a JNK inhibitor) group. (e) EPO plus SB239063 (a p38-MAPK inhibitor) group. (f) EPO plus U0126 (an ERK inhibitor) group. (g) EPO plus AG490 (a JAK2 inhibitor) group. (h) EPO plus Ly294002 (a PI3K inhibitor) group. Nuclei are highlighted by DAPI staining. Scale bar: $50 \mu \mathrm{m}$.

\section{Expression of AQP4 Proteins in Each Group of Cultured Astrocytes}

As expression of AQP4 peaked at $48 \mathrm{~h}$ after rhEPO administration, we selected this time point for further experiments. To reveal the morphology of AQP4 protein in cultured astrocytes, we stained the nuclei with DAPI. In contrast to the polarized distribution in brain tissues, expression of AQP4 protein was found homogeneously distributed in the cytoplasm of cultured astrocytes. Both western blotting and immunofluorescence revealed that rhEPO upregulated AQP4 protein expression in astrocytes $(P<0.05)$, which was inhibited only by SP600125, a JNK inhibitor and SB239063, a p38-MAPK inhibitor, not other inhibitors $(P<0.05$; Figure 7).

\section{DISCUSSION}

In this study, we investigated the effects of $\mathrm{EPO}$ on $\mathrm{BBB}$ after $\mathrm{ICH}$ and tested whether these effects were AQP4 dependent.
EPO activity is closely related to AQP4 expression. It has been reported that $\mathrm{EPO}$ can upregulate AQP4 expression in CNS in various pathological states, including hypoxicischemia and contusive spinal cord injury models. ${ }^{12,23} \mathrm{EPO}$ abolishes upregulation of AQP4 induced by oxygen-glucose deprivation followed by reoxygenation. ${ }^{13}$ Differences in AQP4 expression may depend on the effects of EPO and AQP4 on different models. In this study, we found that intraperitoneal injection of EPO was able to upregulate AQP4 expression at normal stratum as well as surrounding the hematoma after ICH. We investigated the level of expression of EPOR to confirm EPO's effect. Previous studies have revealed upregulation of EPOR because of CNS injury, ${ }^{24}$ which is in agreement with our findings that ICH induced EPOR upregulation. We also demonstrated that EPO injection contributed to increased expression of its receptor both under normal conditions and after ICH at all selected time points. Similar findings have been reported in cerebral 

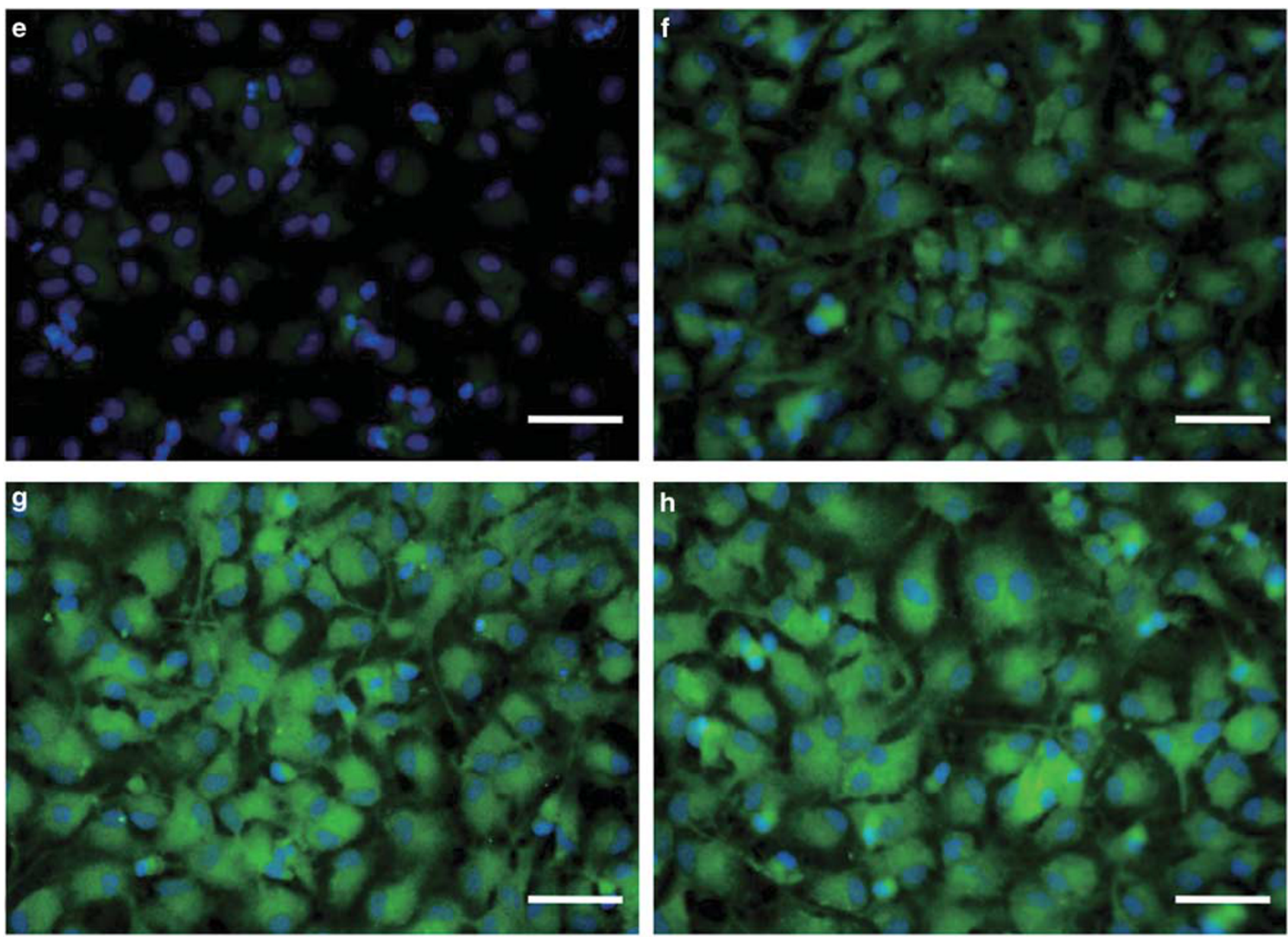

Figure 7 Continued.

ischemia and traumatic axonal injury models. ${ }^{2,25}$ Moreover, the variation in levels of EPOR caused by EPO was similar between $\mathrm{AQP} 4^{+/+}$and $\mathrm{AQP} 4^{- \text {an }}$ mice. Taken together, the above findings suggest that AQP4 is involved in exogenous EPO's effects on BBB.

There have been several studies elaborating the effect of $\mathrm{EPO}$ on $\mathrm{ICH}$, including neurological function improvement, brain edema reduction, cell death inhibition and promotion of neurogenesis. ${ }^{3,4,26}$ However, to date, there has been only one study delineating EPO's effect on BBB after ICH, but it lacks dynamic and continuous observations. BBB is composed of endothelial cells, TJ, astrocyte end-feet and pericytes, and functions to maintain homeostasis of the neuro-parenchymal microenvironment. In this study, we comprehensively evaluated $\mathrm{BBB}$ disruption following $\mathrm{ICH}$ morphologically and functionally. We measured brain water content to determine vasogenic edema resulting from BBB breakdown as well as EB extravasation to evaluate BBB permeability to macromolecules. We observed morphologic alteration of BBB using electron microscopy and examined expression of TJ proteins. Moreover, the three time points selected in our study: 1, 3 and 7 days after $\mathrm{ICH}$, are in line with three important phases: initiation of $\mathrm{BBB}$ injury, aggravation and elimination, respectively, thus making it possible for a continuous observation of $\mathrm{BBB}$ disruption after ICH during the pathological process.

We found that intraperitoneal injections of EPO reduced brain edema and BBB permeability of the hemorrhagic hemisphere, which is consistent with previous reports. ${ }^{3,7}$ In addition, we observed the effect of EPO on BBB ultrastructure that had been altered by $\mathrm{ICH}$, and demonstrated that EPO suppressed the perivascular space widening, TJ opening and capillary endothelial cell swelling. As TJ has essential roles in barrier function and consists of integral membrane proteins, we put emphasis on the three important TJ proteins: occludin, ZO-1 and claudin-5. The results show that EPO upregulated TJ proteins occludin and ZO-1 rather than claudin-5, suggesting the two proteins may be an important target for EPO's protection of BBB after ICH. To date, research on the relationship between EPO and BBB mostly focused on cerebral ischemia models. In these studies, EPO is reported to reduce BBB permeability 
evaluated by several methods, partly restore TJ integrity and upregulate TJ proteins after cerebral ischemia. ${ }^{5,6,27}$ These results reveal the effects of EPO on BBB under pathological conditions, in accordance with findings of this study. We further investigated the mechanisms involved in order to determine whether EPO elicited its protective effects by regulating the expression of AQP4.

To better verify effects of AQP4, we used $\mathrm{AQP} 4^{-1-}$ mice. We demonstrated that $\mathrm{AQP} 4^{-1-}$ mice had more severe $\mathrm{BBB}$ disruption than $\mathrm{AQP} 4^{+/+}$mice after $\mathrm{ICH}$, which was similar to our previous study. ${ }^{11} \mathrm{EPO}$ attenuated $\mathrm{BBB}$ disruption in both types of mice after ICH, but injuries in $\mathrm{AQP} 4^{-1-}$ mice were still more severe. To investigate whether these effects of EPO involved AQP4, we studied the interactions between EPO injection and analyzed the presence of the AQP4 gene by two-way ANOVA with replication. We found interactions between EPO administration and presence of AQP4 gene, indicating that AQP4 is involved in EPO's protective effects on BBB. AQP4 is highly concentrated in astrocyte foot processes surrounding capillaries, which is an important target for BBB integrity maintenance. Under normal state, AQP4 does not alter the ultrastructure of BBB or affect barrier function to macromolecules except water movement, demonstrated by studies using two AQP4 deletion models: AQP4 gene knockout and depolarization of AQP4 protein. ${ }^{28,29}$ Previous studies also highlighted the importance of $\mathrm{AQP} 4$ in maintaining integrity of $\mathrm{BBB}$ in developing individuals. ${ }^{9} \mathrm{AQP} 4$ is regarded to have essential roles to maintain BBB integrity in several models of CNS injuries, including spinal cord injury, subarachnoid hemorrhage and ICH. ${ }^{11,30,31}$ Our previous study found AQP4 suppressed TJ opening and endothelial cell swelling after ICH when compared with the AQP4 ${ }^{-1-}$ mice group. ${ }^{11}$ In addition, AQP4 is believed to be involved in the protective effects of vascular endothelial growth factor (VEGF) and granulocyte colony-stimulating factor on BBB after ICH in our recent work. $^{32,33}$ Along with our current results, these previous studies lead us to conclude that protection of the structure and function of $\mathrm{BBB}$ after $\mathrm{ICH}$ elicited by $\mathrm{EPO}$ is AQP4 dependent. The main target of EPO's effect may be the TJ proteins occludin and ZO-1, but not claudin-5, which is probably because of selective regulation of $\mathrm{TJ}$ proteins by EPO.

Our study demonstrates that EPO upregulated AQP4 with increase of p-JNK, p-p38 and EPOR in cultured astrocytes, and that the inhibitors of JNK and p38-MAPK prevented AQP4 upregulation. This implies that upregulation of AQP4 by EPO binding to EPOR may result from activation of JNK and p38-MAPK signal transduction pathways, which are known to be activated by EPO. ${ }^{34-36}$ Several previous studies reported that a p38-MAPK inhibitor suppressed AQP4 upregulation induced by manganese treatment or hyperosmotic solutions. ${ }^{16,17}$ Moreover, our recent study reveals that the JNK pathway was involved in VEGF's effect on AQP4 upregulation..$^{32}$ These previous results are consistent with our findings in this study concerning the pathways involved in AQP4 regulation. Although ERK may be involved in AQP4 expression, ${ }^{37}$ it was not examined in our study. As a result of the cross-talk that occurs among members of the MAPK family, we speculate that ERK and other signal transduction pathways may also regulate AQP4 expression.

In conclusion, we herein demonstrate through dynamic and continuous observation that EPO protects BBB from disruption after ICH, both morphologically and functionally. The main targets appear to be two TJ proteins, occludin and ZO-1. The effects of EPO are closely related to AQP4 upregulation, as determined by comparison of wild-type and AQP4 null mutant mice. In addition, our study reveals that the AQP4 upregulation by EPO after binding to EPOR may result from the activation of the JNK and p38-MAPK pathways. This study thus provides a double target for the study of the BBB disruption following $\mathrm{ICH}$, which may yield new insights into drug development and treatment.

Supplementary Information accompanies the paper on the Laboratory Investigation website (http://www.laboratoryinvestigation.org)

\section{ACKNOWLEDGMENTS}

This research was supported by grants from the National Natural Science Foundation of China (81171129; 81271295). We thank Professor Gang Hu and Jianhua Ding (Jiangsu Key Laboratory of Neurodegeneration,

Department of Anatomy, Histology and Pharmacology of Nanjing Medical University in China) for kindly providing $\mathrm{AQP}^{-{ }^{-1}}$ mice.

\section{DISCLOSURE/CONFLICT OF INTEREST}

The authors declare no conflict of interest.

1. Wang $Y$, Zhang ZG, Rhodes $K$, et al. Post-ischemic treatment with erythropoietin or carbamylated erythropoietin reduces infarction and improves neurological outcome in a rat model of focal cerebral ischemia. Br J Pharmacol 2007;151:1377-1384.

2. Li Y, Lu Z, Keogh CL, et al. Erythropoietin-induced neurovascular protection, angiogenesis, and cerebral blood flow restoration after focal ischemia in mice. J Cerebr Blood F Met 2007;27:1043-1054.

3. Lee ST, Chu K, Sinn DI, et al. Erythropoietin reduces perihematomal inflammation and cell death with eNOS and STAT3 activations in experimental intracerebral hemorrhage. J Neurochem 2006;96: 1728-1739.

4. Seyfried DM, Han Y, Yang D, et al. Erythropoietin promotes neurological recovery after intracerebral haemorrhage in rats. Int J Stroke 2009;4:250-256.

5. Chi OZ, Hunter C, Liu X, et al. Effects of erythropoietin on blood-brain barrier disruption in focal cerebral ischemia. Pharmacology 2008;82:38-42.

6. Liu K, Sun T, Wang P, et al. Effect s of erythropoietin on blood-brain barrier tight junctions in ischemia-reperfusion rats. J Mol Neurosci 2013;49:369-379.

7. Li Y, Ogle ME, Wallace IV GC, et al. Erythropoietin attenuates intracerebral hemorrhage by diminishing matrix metalloproteinases and maintaining blood-brain barrier integrity in mice. Acta Neurochir Suppl 2008;105:105-112.

8. Papadopoulos MC, Verkman AS. Aquaporin-4 and brain edema. Pediatr Nephrol 2007;22:778-784.

9. Nico B, Frigeri A, Nicchia GP, et al. Role of aquaporin-4 water channel in the development and integrity of the blood-brain barrier. J Cell Sci 2001;114:1297-1307. 
10. Zhou JP, Kong H, Hua XD, et al. Altered blood-brain barrier integrity in adult aquaporin-4 knockout mice. Neuroreport 2008;19:1-5.

11. Tang $Y$, Wu $P, \mathrm{Su} J$, et al. Effects of aquaporin-4 on edema formation following intracerebral hemorrhage. Exp Neurol 2010;223:485-495.

12. Brissaud $\mathrm{O}$, Villega $\mathrm{F}$, Konsman JP, et al. Short-term effect of erythropoietin on brain lesions and aquaporin-4 expression in a hypoxic-ischemic neonatal rat model assessed by magnetic resonance diffusion weighted imaging and immunohistochemistry. Pediatr Res 2010;68:123-127.

13. Tang $Z$, Sun $X$, Huo G, et al. Protective effects of erythropoietin on astrocytic swelling after oxygeneglucose deprivation and reoxygenation: mediation through AQP4 expression and MAPK pathway. Neuropharmacology 2013;67:8-15.

14. Cotena S, Piazza O, Tufano R. The use of erythropoietin in cerebra diseases. Panminerva Med 2008;50:185-192.

15. Sirén $A L$, Fabhauer $T$, Bartels $C$, et al. Therapeutic potential of erythropoietin and its structural or functional variants in the nervous system. Neurotherapeutics 2009;6:108-127.

16. Rao KVR, Jayakumar AR, Reddy PVB, et al. Aquaporin-4 in manganesetreated cultured astrocytes. Glia 2010;58:1490-1499.

17. Yang $\mathrm{M}, \mathrm{Gao} \mathrm{F}$, Liu $\mathrm{H}$, et al. Hyperosmotic induction of aquaporin expression in rat astrocytes through a different MAPK pathway. J Cell Biochem 2013;114:111-119.

18. Yang CS, Tzou BC, Liu YP, et al. Inhibition of cadmium-induced oxidative injury in rat primary astrocytes by the addition of antioxidants and the reduction of intracellular calcium. J Cell Biochem 2008;183:213-221.

19. Villa $\mathrm{P}$, Bigini $\mathrm{P}, \mathrm{Mennini} \mathrm{T}$, et al. Erythropoietin selectively attenuates cytokine production and inflammation in cerebral ischemia by targeting neuronal apoptosis. J Exp Med 2003;198:971-975.

20. Kawasaki T, Kitao T, Nakagawa K, et al. Nitric oxide-induced apoptosis in cultured rat astrocytes: protection by edaravone, a radical scavenger. Glia 2007:55:1325-1333.

21. Sinke AP, Jayakumar AR, Panickar KS, et al. NFkB in the mechanism of ammonia-induced astrocyte swelling in culture. J Neurochem 2008;106:2302-2311.

22. Habas A, Kharebava G, Szatmari E, et al. NMDA neuroprotection against a phosphatidylinositol-3 kinase inhibitor, LY294002 by NR2Bmediated suppression of glycogen synthase kinase-3b-induced apoptosis. J Neurochem 2006;96:335-348.

23. Vitellaro-Zuccarello L, Mazzetti S, Madaschi L, et al. Chronic erythropoietin-mediated effects on the expression of astrocyte markers in a rat model of contusive spinal cord injury. Neuroscience 2008:151:452-466.

24. Hasselblatt $M$, Ehrenreich $H$, Sirén AL. The brain erythropoietin system and its potential for therapeutic exploitation in brain disease. J Neurosurg Anesthesiol 2006;18:132-138.
25. Hellewell SC, Yan EB, Alwis DS, et al. Erythropoietin improves motor and cognitive deficit, axonal pathology, and neuroinflammation in a combined model of diffuse traumatic brain injury and hypoxia, in association with upregulation of the erythropoietin receptor. J Neuroinflamm 2013:10:156-176.

26. Grasso G, Graziano F, Sfacteria A, et al. Neuroprotective effect of erythropoietin and darbepoetin alfa after experimental intracerebral hemorrhage. Neurosurgery 2009;65:763-770.

27. Li Y, Lu ZY, Ogle M, et al. Erythropoietin prevents blood brain barrier damage induced by focal cerebral ischemia in mice. Neurochem Res 2007;32:2132-2141

28. Haj-Yasein NN, Vindedal GF, Eilert-Olsen $M$, et al. Glial-conditional deletion of aquaporin-4 (Aqp4) reduces blood-brain water uptake and confers barrier function on perivascular astrocyte endfeet. Proc Natl Acad Sci USA 2011;108:17815-17820.

29. Eilert-Olsen M, Haj-Yasein NN, Vindedal GF, et al. Deletion of aquaporin-4 changes the perivascular glial protein scaffold without disrupting the brain endothelial barrier. Glia 2012;60:432-440.

30. Kimura A, Hsu M, Seldin M, et al. Protective role of aquaporin-4 water channels after contusion spinal cord Injury. Ann Neurol 2010;67: 794-801.

31. Tait MJ, Saadoun S, Bell BA, et al. Increased brain edema in AQP4-null mice in an experiment model of subarachnoid hemorrhage. Neuroscience 2010;167:60-67.

32. Chu H, Tang Y, Dong Q. Protection of vascular endothelial growth factor to brain edema following intracerebral hemorrhage and its involved mechanisms: effect of aquaporin-4. Plos One 2013;8: e66051-e66064.

33. Chu H, Tang Y, Dong Q. Protection of granulocyte-colony stimulating factor to hemorrhagic brain injuries and its involved mechanisms: effects of vascular endothelial growth factor and aquaporin-4. Neuroscience 2014;260:59-72.

34. Bose C, Udupa KB. Erythropoietin enhancement of rat pancreatic tumor cell proliferation requires the activation of ERK and JNK signals. Am J Physiol Cell Physiol 2008;295:C394-C405.

35. Burger D, Xiang F, Hammoud L, et al. Role of heme oxygenase-1 in the cardioprotective effects of erythropoietin during myocardial ischemia and reperfusion. Am J Physiol Heart Circ Physiol 2009;296: $\mathrm{H} 84-\mathrm{H} 93$.

36. Ben-Ari Z, Zilbermints V, Pappo O, et al. Erythropoietin increases survival and attenuates fulminant hepatic failure injury induced by D-galactosamine/lipopolysaccharide in mice. Transplantation 2011;92: $18-24$.

37. Li Y, Chen G, Zhao J, et al. 2,3,7,8-Tetrachlorodibenzo-p-dioxin (TCDD) induces microglial nitric oxide production and subsequent rat primary cortical neuron apoptosis through p38/JNK MAPK pathway. Toxicology 2013;312:132-141. 